\title{
Kernos
}

Revue internationale et pluridisciplinaire de religion grecque antique

$17 \mid 2004$

Varia

\section{Le sparagmos, un rite de magie fécondante}

\section{Monique Halm-Tisserant}

URL : http://journals.openedition.org/kernos/1405

DOI : 10.4000/kernos. 1405

ISSN : 2034-7871

\section{Éditeur}

Centre international d'étude de la religion grecque antique

Édition imprimée

Date de publication : 1 janvier 2004

ISSN : 0776-3824

\section{Référence électronique}

Monique Halm-Tisserant, «Le sparagmos, un rite de magie fécondante », Kernos [En ligne], 17 | 2004,

mis en ligne le 22 avril 2011, consulté le 30 avril 2019. URL : http://journals.openedition.org/

kernos/1405; DOI : 10.4000/kernos.1405 


\title{
Le sparagmos, un trite de magie fécondante
}

\author{
"Cette agitation des gonades, que ce soit \\ sous la forme du rut ou de la floraison des arbres..." \\ J. BRosse, Mythologie des arbres, 1993, p. 137.
}

Propoléos, Ouresiphoitès, Dionysos qui entraîne vers les cimes, mais qui dans le même temps présida aux institutions des cités (au théâtre, au symposion), fut l'objet de rituels divers qui, de manière réductrice, délimitent aux yeux des modernes le «dionysisme» et dont le ménadisme constitula assurément, avec les mascarades, les phallophories, l'une des facettes les plus primitives.

Consécutif à l'oribasie, la chasse au petit gibier à laquelle s'adonnaient sur les montagnes' les adeptes du dieu, le sparagmos, perçu comme l'étape intermédiaire du rite ménadique, devait être suivi (du moins selon le déroulement séquentiel qu'en ont restitué les modernes) de la manducation des parts crues des animaux capturés, puis déchirés vifs.

Cristallisant sur elle l'argumentaire des allégations des apologistes chrétiens qui, tel Clément d'Alexandrie ${ }^{2}$, ne manquèrent pas, pour diffamer les pratiques "païennes», de projeter sur la soi-disant manducation les mystères de l'eucharistie, l'ômophagie est pourtant contraire aux conduites alimentaires orphiques qui, dès le $\mathrm{v}^{\mathrm{e}}$ siècle av. J.-C., avaient contaminé le dionysisme. Bien qu'y soient paradoxalement évoqués les « repas ômophages » accomplis par l'adepte, Porphyre cite dans le De abstinentia comme un exemple archétype d'abstinence carnée le fragment 472 des Crétois ${ }^{3}$ d'Euripide. Or, dans un makarismos, le myste se fait l'écho du bios orphikos que doit mener tout bacchant et qui comporte, en particulier, l'interdit de consommer « toute nourriture vivante $»$.

\footnotetext{
1 Le cri de ralliement des Bacchantes est els ö $O$ os ("à la montagne !»), dans la fiction (22 occurrences les Bacchantes d'Euripide, cf. A. MORFAu, «Actéon, Orphée, Penthée: mise en abyme et initiation manquée dans les Bacchantes d'Euripide ", Kentron 14 [1998], p. 23-27),

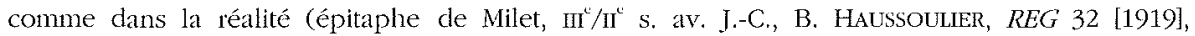
p. 256; A.F. JACCOTTET, Choisir Dionysos, Zürich, Akanthus, 2003, p. 250, 149).

ClÉM. ALEX., Protiept. II, 12; XII, 119, 1.

3 De abstinentia IV, 18, 10-19 (fr. 472 des Crétois, TGRF 475) : "Devenu myste de Zeus Idéen, j'ai célébré les repas ômophages du bouvier Zagreus, le rôdeur nocturne, et brandissant les torches pour la Mère de la montagne, purifié, parmi les Courètes j'ai été appelé Bacchos. Portant des vêtements tout blancs, des mortels je fuis l'accouchement et n'approche pas l'urne; je me garde de toute nourriture vivante " (trad. M. Halm-Tisserant).
} 
C'est pourtant sur le cliché de la ménade ômophage que, depuis Niestzche, s'est élaborée la vision qui s'impose encore aujourd'hui d'un dionysisme sauvage ${ }^{5}$ dont la marginalité - confortée par des références à l'anthropologie - servit opportunément la dialectique de la réflexion structurale.

Je ne développerai pas ici les raisons qui m'ont incitée à remettre en cause la réalité de l'ômophagie, mais souhaiterais rappeler quelques-unes des données sur lesquelles a été fondée mon argumentation.

Précisément assurés de la réalité de la pratique carnassière, les traducteurs ont souvent forcé le sens des témoignages littéraires classiques, par trop rares, mentionnant le terme (en particulier l'incise, grammaticalement embarrassante, des vers 139-140 des Bacchantes), contribuant, de manière tautologique, à ajouter foi à l'ômophagie rituelle ${ }^{7}$. Censée être le point culminant du rite, jamais, pourtant, la consommation des chairs crues ne fut montrée dans les représentations figurées; pas plus qu'elle ne fut mentionnée dans les Bacchantes, une tragédie qui, en filigrane des événements mythiques, constitue le témoignage majeur qui nous soit parvenu sur les pratiques dionysiaques.

Les auteurs de l'époque archaïque semblent avoir ignoré la manducation, alors que certains, parmi ceux qui, tels Lucien ${ }^{8}$ et Oppien?, vécurent à l'ère chrétienne, dénoncèrent les clichés relatifs à la bestialité des ménades, les l'exacerbant jusqu'au paroxysme du comportement carnivore. En quête de l'origine de l'épiclèse Omestès et évhémériste avant l'heure, Alcée ${ }^{10}$ relie

Ia manducation rituelle surprend, tant par les prouesses physiques qu'elle requiert (Arnobe, Constance, Firmicus Maternus, d'écrivent les Ménades déchirant de leurs dents un taureau vivant !) que par l'étrangeté que représente l'ingestion d'une viande fraîchement abattue, impropre à la consommation en raison de sa dureté, puisque n'ayant pas subi, comme dans le sacrifice civique, l'ébullition préalable au rôtissage, destinée à l'attendrir.

5 J.-P. Vernant, P. VIDAL-NAQUET, Mythe et Tragédie II, Paris, 1986, p. 240; A. Henkichs, «La donna nella cerchia dionisiaca », in Le donne in Grecia, 1985, p. 273.

${ }^{6}$ L'antithèse permettait d'opposer le rituel dionysiaque au sacrifice civique et d'inscrire l'analyse comparative dans la dialectique levi-straussienne du «cru et du cuit »... Récemment, les historiens des religions ont fait part de leurs doutes face à la sauvagerie prêtée aux pratiques dionysiaques (HENRichs, l.c. [n. 5], p. 249: "un intera generazione di studiosi ha interpretato l'omofagia menadica alla luce di un rito cruento praticato dalle sette musulmane nel Marocco "; p. 273 : «una volta suggerii, ma ora sono meno siccuro che il mito delle menadi conserva il ricordo dell'antica ferocia tribale $》)$, voire, trop timidement, nié la réalité de l'ômophagie (M. DARAKI, Dionjsos, Paris, 1985, p. 62, note 67 : "le vrai manger dionysiaque est végétarien ").

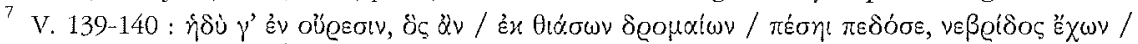

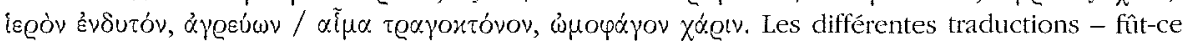
au mépris du texte - révèlent l'embarras que fait régner la prétendue ômophagie... (p. ex. : H. Jeanmatre, Dionjsos. Hisloire du culle de Bacchus, Paris, $1978^{2}$ [1951], p. 252 : "à la chasse du bouc, charisme de la chair crue "; J. Roux, Les Baccbantes, Paris, Belles Lettres, 1972, p. 120 : "faisant sa proie du bouc qui meurt, perdant son sang, / délice de la chair dévorée toute vive ». Voir, n. 83, la traduction que je propose du passage.

${ }^{8}$ LuCIEN, Opurscules 4, Dionysos, Vulg. 54, trad. J. Bompaire (CUT) : " en tous cas les troupeaux ont été dépecés vivants, car ce sont des mangeuses de chair crue. »

" OPPIEN, Cynégétique IV, 13-21, vers 305-307.

${ }^{10}$ Fr. 306 Ea, col. II, Alcée, Fr. I, trad. G. Liberman (CUF); ibidem, I, 129, 10 : Omèslas. 
l'adjectif, non point à Dionysos, mais au nom d'un personnage mythique, s'écartant ainsi de la tradition puisque que la plupart, précise-t-il, " disent que c'est à cause des ménades qui déchirent à vif les bêtes ». Étrange étiologie qui relie le Dionysos "Carnassier » à la pratique du sparagmos et non point à celle de l'ômophagie! Après avoir, comme Lucien dans une extravagante "latia », accumulé les outrances et peint les ménades «armées de griffes meurtrières », avides de sang, Oppien les réhabilite, réfutant les excès de leurs comportements nés de l'imagination de poètes "menteurs "

Au silence de la fiction, poétique et plastique, s'ajoute le laconisme des historiens. N'est-il pas troublant de constater que l'ômophagie ne figurait pas au nombre des chefs d'accusation (excès, débauches, meurtres) portés dans le réquisitoire du consul Posthumus contre les sectateurs étrusco-campaniens à l'origine du scandale des Bacchanales à Rome, en $186^{12}$ ? Si la manducation avait fait partie des pratiques que l'on entendait dénoncer, nul doute qu'elle aurait été mentionnée dans les minutes du procès relaté par Tite-Live.

Tenir l'ômophagie pour l'acmé de l'action rituelle eut pour conséquence de relativiser l'importance du sparagmos dont on a par trop négligé d'étudier le déroulement comme la symbolique. L'analyse des nombreuses images consacrées au dépècement animal - ou humain, lorsqu'il a été inséré dans la mythologie thébaine - révèle la récurrence d'actions et de gestuelles assurément significatives des modalités de ce rite que les témoignages littéraires évoquant le dépècement confirment au demeurant. Le rapprochement des représentations et des sources littéraires d'une part, du déchirement dionysiaque avec d'autres rites qui le tirent de son isolement et de sa sauvagerie d'autre part, incite à faire du sparagmos l'acte essentiel du rituel et à lui accorder une finalité particulière, incompatible avec la pratique ômophagique.

\section{Le sparagmos}

Emprunté à la famille lexicale du verbe $\operatorname{sparass}^{13}$, le vocabulaire du sparagmos renseigne sur les techniques du rite. Son association aux préfixes dia et apo, dans les Bacchantes notamment, ajoute au sens premier de «mettre en pièces » l'acception de dispersion (pour dia: $\delta \iota \alpha \pi \dot{\alpha} \sigma \sigma \omega$, v. 1220)

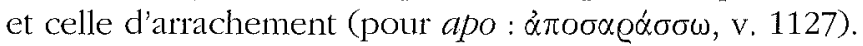

Les « descriptions » les plus circonstanciées de ce rite émanent de la fiction tragique, puisque Euripide n'a pas consacré moins de 252 vers à la narration de cet acte, relatant dans le drame, par la bouche d'un bouvier et d'un serviteur de la maison royale, deux sparagmoi successifs : le dépècement des troupeaux sur le Cithéron par les sectatrices lydiennes du dieu (vers 660 à

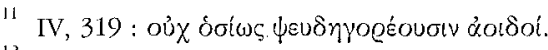

12 TITE-LIVE, XXXIX, 8-19; J.M. PALler, Bacchanalia, Rome, 1998, p. $28-56$.

${ }^{13}$ On fait dériver sparassô du verbe spaô (P. ChañTaine, Dict. étymologique de la langue grecque IV, s.u., p. 1032) qui signifie disloquer en tirant et qui est utilisé, dans le composé

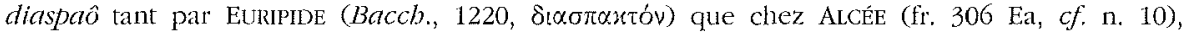
Diodore, III, 6 et le ps.-ÉRATOSTHÈne (Katerismoi, 24, à propos de la mort d'Orphée). Le verbe diàpazô (déchirer), moins usuel, ne se rencontre que clans les Opuscules de Lucien (n. 8). 
774), suivi de la mise en pièces de Penthée par les ménades thébaines, poussées à la folie par Dionysos dans le quatrième stasimon et la cinquième scène (vers 1020 à 1152). Si, tout en imprégnant le rituel de surnaturel par la nature inhabituelle des victimes (génisses, taureaux, boufs), la première évocation brosse un tableau bucolique de l'extase ménadique, la seconde relate un sacrifice humain qui, bien que dévoyé, demeure néanmoins calqué sur les modalités du sparagmos animal. C'est à ce titre qu'il doit d'être pris en compte dans une étude consacrée à ce rite.

\section{Techniques du sparagmos}

Anodines en apparence, les images suggèrent parfois le sacrifice dionysiaque. En amont de l'action, ménades et satyres ${ }^{14}$, parfois Dionysos Mainoménos lui-même ${ }^{15}$, tiennent par les pattes ou par la queue, avec plus ou moins de violence - selon un schéma plastique qui évoque l'attitude de la Potnia archä̈que -, la victime qu'ils s'apprêtent à immoler. Prémonitoire de la mise en pièces, la manipulation de l'animal paraît avoir été à ce point emblématique du rituel ménadique qu'un faon, comme en lévitation, mais plaqué contre le corps de la prêtresse qui semble le maintenir, a été associé aux attributs symboliques du sacerdoce dionysiaque que sont le thyrse et le canthare sur le couvercle d'un sarcophage étrusque du Iv siècle av. J.-C. ${ }^{16}$ (Pl. I, 2).

Mais il advient que, faisant en quelque sorte transition entre les séquences rituelles, un peintre imprime au geste de la manipulation un élan, identique à celui qui accompagne le jet de l'animal déchiré ${ }^{17}(P l . V I, 1)$.

\section{La section en deux}

Pratiqué à mains nues, Euripide se plaît à le souligner à plusieurs repri$\operatorname{ses}^{18}$, le sparagmos se déroule selon deux phases successives : la section en deux et l'arrachement des membres de l'animal.

Seul Euripide, dans les Bacchantes, évoque au vers 737, la technique du sectionnement au moyen de l'adverbe dicha: l'initiatrice du sparagmos

14 Les représentations, nombreuses, émanent de la figure noire comme de la figure rouge attique : LIMC VIII, s.v. Mainades, 524, 7; 526, 25; 529, 35; 538, 63; voir, p. ex., le tondo de la coupe, coll. Borowski, de Douris : H.A. SHAPIRO, «Poet and Painter», Quademi Ticines 23 (1994), pl. VII; la coupe de Tarquinia, d'Oltos, (ici Pl. I, 1 ).

15 Hydrie de Caere, Musée de Vienne IV, 3577, P. de l'Aigle, J.M. HemelriYK, Caeretan Hydriae, Mayence, 1984, 14, pl. 36-38, LIMC N, s.v. Hépläistos, 103a.

${ }^{16}$ Sarcophage de Nenfro, Mus. Brit. BM D 22, seconde moitié du IV s. av. J.-C., LLMC VIII, 545, 114. Mềme association (cratère, thyrse, faon + autel) disposés sur les axes de la coupe de Macron, Musée de Berlin 2290, ARV 462, 48, voir M. HaLm-Tisserant, "Autour du mannequin dionysiaque $»$, Hephaistos 10 (1991), p. 70, n 25, PI. II.

17 Coupe du Louvre G 160, Macron, ARV 478; M.C. VILlanueva-PUig, "À propos d'une ménade aux sangliers », RA (1983), p. 243, fig. 5.

18 Bacch., 736, 745, 1219. C'est tardivement et dans le mythe de Penthée qu'apparaissent les épées aux mains des femmes; accessoire qui caractérisera la Ménade hellénistique, notamment dáns le domaine de la sculpture. 


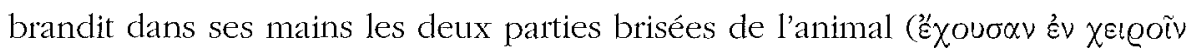
$\delta(\chi \alpha)$.

Mais, alor's que les textes n'y font guère allusion, de manière répétitive, les compositions figurées donnent à voir l'instant de la section. Destinée à briser l'échine de la victime, elle s'effectue transversalement et non point longitudinalement, comme c'est l'usage dans les techniques d'abattage ${ }^{19}$. Elle peut être le fait d'un seul participant ( $P l . I V, 1)$. Mais le satyre accroupi, un pied posé sur l'arrière train du cerf qu'il maitrise, tandis qu'il s'est saisi de ses ramures afin de lui rompre l'échine, fait exception sur une coupe d'Onésimos ${ }^{20}$ ( $P$ l. I, 4). Car c'est le plus souvent dans la station debout que les adeptes sont représentés, saisis dans l'action d'écarteler l'animal. Le Peintre de l'Ange volant $^{21}$, le Peintre de Shuwalow ${ }^{22}$, ont suggéré les tractions contraires sur les antérieures et la queue de la victime, toujours maintenue tête-bêche par le sacrificateur $(P l . I V, 2)$. Fréquemment les membres du thiase opèrent à deux, tirant, chacun, à hue et à dia sur le corps de l'animal (Pl. II). La plus ancienne figuration apparaît sur un lécythe à figures noires de qualité médiocre, attribué au Peintre d'Haimon, qui introduit paradoxalement le sparagmos d'un faon dans le contexte du rituel devant l'idole dionysiaque ${ }^{23}$. Que ce soit sur les peintures de vases de la fin du vi siècle ou dans le répertoire des peintres italiotes du $\mathrm{IV}^{\mathrm{c}}$ siècle, la technique du déchirement de l'animal, toujours tenu à l'horizontale, ne varie guère. Tout au plus l'orientation des sacrificateurs, installés dos à dos, exacerbe-t-elle la dynamique de la section. Agencée sur les vases attiques de l'époque post-parthénonienne ainsi que sur des exemplaires italiotes $^{24}$ ( $\left.P l . I I, 1 ; I I I, 1\right)$, la composition divergente et plus théâtrale dominera dans les représentations des toreutes et des sculpteurs de l'époque hellénistique sur lesquelles, de surcroît, la section de l'animal est accomplie ${ }^{25}$.

Certains peintres choisirent de focaliser l'action en aval, sur l'instant consécutif à la section, ajoutant à la violence de l'acte, puisque la victime n'est plus présentée dans son intégrité physique. Dès 530, les imagiers peignirent, en effet, soit les ménades, soit Dionysos Mainoménos ( $P l . I V, 1 ; V, 1)$, bras levés ou écartés, brandissant les parts de l'animal dont le corps vient tout juste de

19) Voir les terres cuites des dépouilles des porcelets éventrés découverts dans le Thesmophorion de Thasos, Cl. Rolley, BCH 89 (1965), p. 470-471, fig. 30-31; A. Mutler, Les terres cuites volives du Thesmophorion, Athènes, 1996 (Eludes Thasiennes, 17), p. 448, n 1138-1141, pl. 138.

20 C. d'Onésimos, A. ScHNAPP, Le chasseur et la cité, chasse et érotique dans la Grèce ancienne, Paris, 2000, fig. 58.

21 St. Pétersbourg 604, J.D. BeAzLEy, VAmer., Rome, 1967, 59, 5.

22 Skyphos du P. de Schuwalow, ARV 1212; LIMC VII, s.v. Mainades, 13.

23 Lécythe d'Éleusis 2409, Classe d'Athènes 581, $A B L 504,18$; F. Frontisi-Ducroux, in L'Association dionysiaque dans les sociétés anciennes, Rome, 1986, p. 89, fig. 9.

24. Couvercle de pyxide, Mus. Brit. E 775, ARV 1328, 92; LIMC VII, ib., 529, 33; cratère en d. apulien, Gotha, P. de Berkeley, RVAP 1, 268, 54; LIMC VIII, ib., 534, 45; Lékanè d'Odessa, H. METzGER, Les représentations dans la céramique altique du $\mathrm{VV}^{\prime}$ siècle, Paris, 1951 (BEFAR, 172), p. 56, $\mathrm{n}^{\circ} 38$, PL. I, 3; LIMC VIII, $i b ., 532,40$.

25 Cratères de Derveni, de Berlin, E. GIOURE, Ho Krateras tou Derveniou, Athènes, 1978, pl. 19 et pl. 105; reliefs du type de la Chimairophonos, attribué à Callimaque, LLMC VIII, ib., 549, 144. 
se rompre $(P l . I V)^{26}$. Jets de sang, débris organiques qui s'échappent des parties sectionnées, confèrent à l'acte un indéniable réalisme. La représentation d'éléments anatomiques sanguinolents n'a probablement pas été dictée par la seule fantaisie, mais peut faire allusion à la symbolique dont étaient grevés dans le rite les viscères palpitants de victimes démembrées vives ${ }^{27}$. Leur présentation ostentatoire sur ces images n'est d'ailleurs pas sans évoquer les terres cuites démétriaques, découvertes dans le Thesmopborion de Thasos, qui exhibent les entrailles de porcelets éventrés ${ }^{28}$.

La technique de la section est identique dans les illustrations de la mort de Penthée où, toujours, en raison de l'effort qu'impose la stature du roi, les meurtrières opèrent de conserve. Aussi, à la suite de la plus ancienne version, élaborée par Euphronios, a t-on représenté le corps du roi, sectionné : c'est un homme-tronc qu'agrippent par les bras les ménades meurtières ${ }^{29}$. Sur une coupe de la Collection Borowski, Douris, soucieux comme il se doit dans le sparagmos animal de rendre les détails anatomiques, a reproduit même les os arrachés à la cavité iliaque, faisant saillie sous la cage thoracique ${ }^{30}(P l . I I I, 2)$.

\section{Le démembrement}

La section accomplie, les adeptes s'emploient à démembrer les parts de la victime.

Soumis aux contraintes que leur imposait la technique qu'ils exerçaient, les peintres se sont le plus souvent bornés à montrer la section en deux de l'animal, alors qu'ils représentèrent avec complaisance l'arrachement des membres de Penthée que ses proportions humaines permettaient de reproduire plus lisiblement dans le cadre de l'image. Toutefois, sur une coupe de Macron conservée dans la Collection Robinson, loin de tenir les trains avant et arrière de la victime, une ménade brandit les pattes postérieures de l'animal mis en pièces, à preuve que le démembrement devait être également pratiqué sur le

26 Ménade, p. ex. Hydrie apulienne de Munich 3267, RVAp I, 8, 105. Seul le P. d'Achille, sur une amphore de la Bibl. Nat. 357, a occulté en partie la violence, en figurant de dos la ménade qui déchire un faon (ici $P l . I V, 4$ ) $A R V$ 987, 2, LIMC VII, $i b ., 531,38$. Dionysos : Myson, fr. de coupe d'Athènes, J.J. MAFFre, "Quelques scènes mythologiques... Dionysos mainomenos », RA (1982), p. 203-207 (p. 203, fig. 5); stamnos du Mus. Brit. P. de Brygos E 439, ARV 298; LIMC VIII, ib., 312 (Pl. IV, 3); Fr. d'Athènes, RA (1982), p. 206; fr. de cratè̀e du P. d'Altamura, $A R V$ 592, 33; CVA, Hollande I, Musée Scheurleer I, pl. 3, 2; hydr., coll. privée, P. d'Altamura, ARV 605, 65 bis; LLMC III, s.v. Dionysos, 473; Th. Carpenter, in Th. CARPEnter, Ch. A. FAraone (éds), The Masks of Dionysos, New York, 1993, p. 186, fig. 7 (ici Pl. V, 1).

${ }_{27}$ Voir p. 132, la double acception du terme sparagmos.

28 Thasos, cf. n. 19.

29 Psykter de Boston 10. 221, ARV 16, 14; LWMC VI, s.v. Pentheus, 39; Euphronios, peintre à Athènes, Paris, 1990, p. 162-163, n 32; stamnos d'Oxford 1912.1165, P. de Berlin, LIWC VI, $i b$., 42 (Pl. VI, 3); c. de Toronto, coll. Borowski, Douris, ARV 452, 3; LIMC VI, ib., 43 (Pl. III, 2); lékané du Louvre G 445, LIMC VII, ib., 24; E. POTTIER, Vases Loume III, pl. 145; hydrie du Céranique d'Athènes, P. de Meidias, ARV 1313, 6; LIMC VI, ib., 25; WDAICA) 105 (1990), p. 163178, pl. 25-30; cratère du Centuripe, coll. pr. Catane, ASAA NS 1-2 (1939-40), p. 140, 3; cratère en Cal. Apulien, Ferrare 20482, atelier clu P. de Darius, RVAD I, 180, III, pl. 59, 5; LIMC VII, ib., 6.

30 Cf. note précédente. 
petit gibier $(P l . V, 2)^{31}$. Tout comme la brisure de l'échine, l'arrachement des membres s'effectue par des tractions antithétiques, destinées, cette fois, à déboîter les articulations.

La technique est relatée dans le détail par Euripide dans le récit de la mort de Penthée. De son pied calé, Agavé cherche effectivement à faire levier pour désarticuler les membres de son fils : "elle prend des deux mains (le) bras gauche (de Penthée) et le pied posé (verbe antibainô) sur le flanc de cet infortuné, lui arrache l'épaule ${ }^{32}$.

Ce n'est pas fortuitement que, dans des visions qui préfigurent le démembrement du souverain thébain, Euripide a à deux reprises évoqué des « leviers » : en proie à la possession, Penthée a pensé s'en servir pour arracher le Cithéron de ses bases (anaspaô) avant que de, curieusement, le lancer pardessous son épaule ${ }^{33}$. Alor's que les tentatives de déracinement au moyen des leviers n'ont pas abouti ${ }^{34}$, l'arbre, au faîte duquel Penthée était venu épier les ménades, est finalement déraciné par "mille mains (qui) se portent sur le sapin et l'atrachent du sol» (v. 1110). Le verbe anaspaô se voit associé à la mention des mains innombrables, évoquées dans les mêmes termes lors du dépècement des génisses, afin de faire, comme le levier, allusion aux gestes du démembrement et de la lacération. Car l'arrachement des membres est suivi dans le mythe thébain d'une curée, destinée à mettre à nu les os et qu'Euripide évoque au moyen des verbes $\alpha \pi \circ \sigma \pi \alpha \varrho \alpha ́ \alpha \sigma \sigma \omega$ (arracher en lam-

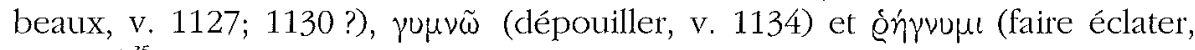
v. 1130$)^{35}$.

Plus crûment que dans les évocations littéraires, sur le psykter d'Euphronios, comme sur le stamnos du Peintre de Berlin, les lambeaux informes et les masses sanguinolentes figurant les viscères que tiennent dans leurs mains les ménades ont été représentés, violemment colorés au moyen de rehauts ( $P l$. $V I, 3)$.

La constance des gestes reproduits sur les monuments qui s'échelonnent entre le $\mathrm{VI}^{\mathrm{e}}$ et le $\mathrm{IV}^{\mathrm{e}}$ siècle démontre que les représentations font référence à

31 C. de la Coll, Robinson, Baltimore, $A R V 463,52$; $C V A$, USA, Robinson. Coll. II, pl. XVI, 1 ab et p. 18 (ici, Pl. VI, 2). Sur une péliké de Berlin 3223 (ARV 586, 47; LIMC VIII, s.t. Mainades, 543 , 95), d'inspiration plus théâtrale, la ménade armée d'un coutelas brandit un cuisseau de la victime démembrée $(P l . V, 3)$. Même type de scène : cratère apulien de Zurich, RVA $D \mathrm{I}, 51,43, \mathrm{P}$. de Tarporley, LLMC VIII, ib., 533, 42.

32 V. 1127 : $\alpha \pi \varepsilon \sigma \pi \alpha \varrho \alpha \xi \xi v$ désigne l'arachement. Dans l'évocation qu'il a laissée du même moment, dans l'Tdylle XXVI, Théocrite use, en revanche, du verbe exarassô pour décrire l'éxérèse de l'omoplate du roi.

${ }^{33}$ Vers 949. Le geste est exprimé par le verbe bypoballo.

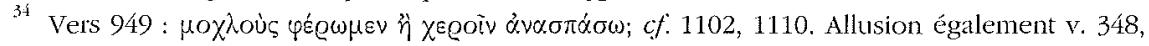
dans les menaces proférées contre Tirésias.

${ }^{35} C f$. Chantraine, $D E L G$, p. 971. La violence du démembrement cesse de surprendre dès lors qu'on rattache l'acte à d'autres techniques sacrificielles marginales, notamment au dépècement perpétré dans le Mégaron de Lycosoura, dont Pausanias décrit les écarts et qui commandait aussi aux participants de "détacher en coupant (apekopse) un membre au hasard» - des victimes vivantes qu'ils immolaient à la Despoina: PAUs., VIII, 37, 8; M. JosT, Sanctuaires et cultes d'Arcadie, Paris/Athènes, 1985, p. 326. 
un rite. S'il s'était agi d'images inspirées par la seule fiction, il y a fort à parier que les peintres auraient, durant les deux cents années où de telles scènes furent reproduites, introduit davantage de variantes et de fantaisies, ne seraitce qu'en raison de facteur's de style et de mode.

La victime une fois débitée, devait débuter la dernière séquence du rituel dont la battue et le démembrement n'avaient été que le prélude : l'ômophagie collective...

Mais, dans les Bacchantes, on l'a rappelé, ni la viande des génisses, ni les chaits du roi ne sont ingérées... Dans une allusion parodique à la mise en pièces qui trouve un précédent dans la représentation du démembrement d'une outre par un satyre, sur une coupe du Peintre de Pistoxénos, c'est une sandalette et un oripeau qui ont été lacérés dans les Grenouilles en l'honneur de $\operatorname{Iacchos}^{36}$ ! Pour quelles raisons aurait-on dans les deux cas tiré un parti comique du sparagmos, sans que soit tournée en dérision l'ômophagie? sinon parce que le démembrement qu'on raillait constituait bel et bien l'acte archétype du rite dionysiaque?

$\mathrm{Si}$, dans les différents témoignages littéraires, les chairs ne sont pas dévorées, c'est que, loin d'être de l'ordre de la consommation, le but du sparagmos était de mettre en pièces la victime, afin de permettre le déroulement de l'ultime séquence, le lancer rituel des parts qui conférait sens et efficacité au sacrifice ménadique.

\section{Le lancer rituel}

Lorsque les animaux chassés avaient été sectionnés, puis démembrés, leurs reliefs faisaient l'objet d'une dispersion par les membres du thiase, selon une technique codifiée dont les sources littéraires, comme l'imagerie, concourent à livrer les modalités ${ }^{37}$.

Le serviteur de la maison de Penthée évoque, au vers 1133 des Bacchantes, la procession des filles de Cadmos qui se rendent vers le lieu de la dispersion : "l'une portant un bras, une autre un pied avec la chaussure même ${ }^{35} \ldots$ »

Le jet n'est pas à proprement parler décrit par Euripide qui, sitôt l'évocation du défilé des Cadméennes, enchaîne sur l'issue du rituel. Il a toutefois précisé, au v. 1136, que les lambeaux ont été jetés, car, «toutes de leurs mains ensanglantées lançaient, comme on lance une balle, les chairs de Pen-

36 ARISTOPHANE, Gr, 404-405 (verbe kataschizô). À double sens, la parodie fait aussi, au premier degré, allusion à l'usure des vêtements qu'ont provoquée les ébats rituels. Coupe de Leipzig, du P. de Pistoxénos, A. MitCHell, "Une outre outrée », Ktèma 25 (2000), p. 115-122, pl. 1.

37 Seules les Cadméeennes agissent sous l'empire de la folie. Le sparagmos des bovidés, dans les Baccbantes, 683, débute au réveil de la catalepsie provoquée par la transe. L'accès à la mania n'était pas - semble-t-il - une condition préalable (voir, p. 128, le règlement de Milet), la ritualisation des gestes supposant davantage la pleine conscience des officiantes.

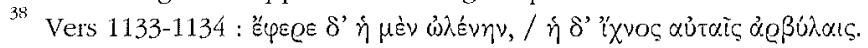


thée $\mathrm{e}^{39}$ ». Sans que le recours à la description soit nécessaire à son évocation, le vocabulaire utilisé par le Tragique éclaire sur les modes de la dissémination ${ }^{\text {"I }}$. Particulièrement fréquent dans les Bacchantes, le verbe diapherô, également employé par Oppien, traduit l'action de disperser. L'emploi de riptô et de son composé diarhiptô (chez le pseudo-Ératosthène) connote toutefois mieux la dynamique de l'éparpillement, introduisant la nuance que, tel un disque, les parts sont jetées avec un élan préalable ${ }^{41}$. La clispersion qui imposait, pour l'efficacité du rite, de répartir les chairs sur la plus grande aire possible, n'est dans les Bacchantes suggérée qu'a posteriori. Témoin du premier démembrement qu'il relate, le bouvier précise que les sabots et les lambeaux des bovidés sont demeurés accrochés aux arbres (vers 740). Après le déchirement de Penthée (scène VI), Cadmos se met en quête des débris du corps de son petit-fils qu'il rapportera sur une civière, afin de le reconstituer sous les yeux des spectateurs. Les conséquences de la dispersion sont perceptibles derrière les propos d'Agavé, qui, ayant recouvré la raison, s'inquiète de savoir si l'on a trouvé (vers 1298) pour les rassembler les fragments du corps ("a-t-on correctement emboîté ses membres dans leurs articulations? "). Le jet rituel a même été à l'origine des difficultés qu'a représenté la collecte des reliques (vers 1299), découvertes "éparpillés » sur les flancs de la montagne (vers 1220).

D'autres récits de sparagmos font encore allusion à la dissémination par le jet. Ovide qui narre à son tour la mort de Penthée dans les Métamorphoses indique que son corps déchiré est «épars en mille lieux». Oppien, dans la Cynégétique, décrit les carcasses animales que, par jeu, l'enfant Dionysos, après les avoir lancées, rend miraculeusement à la vie, encore dispersées sur le sol ${ }^{42}$. Même lorsque Nonnos évoque dans les Dionysiaca la manducation d'Actéon par les chiens de sa meute, un mythe à l'évidence contaminé par les modalités de la mort de Penthée, il fait allusion à la dispersion, puisque les os ont été non seulement retrouvés à même la terre mais très espacés, "à l'écart les uns des autres.. », "restes gisants, ... à grand mal recueillis par la mère »".

La règle, dans l'iconographie de la mort de Penthée, semble avoir été de suggérer le lancer par une scène d'arthtrophorie, comparable à la macabre procession du drame euripidéen dans laquelle chaque ménade emportait une partie du corps démembré. La fixité propre à l'image peinte rendant malaisé la figuration du dynamisme que suppose la dissémination a contraint les artisans de plier les compositions vasculaires au rythme itératif de la frise. De

39 OvDDE, Mét. III, 629, évoquera aussi le défilé des femmes, Inô emportant le bras gauche de Penthée.

40) Ce verbe est plus fréquemment employé dans les deux récits de sparagmos que ceux de la

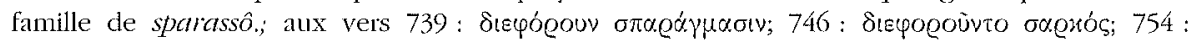

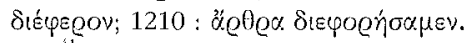

${ }^{41}$ Bacch., 741; ps,-Ératosthève, cf. n. 13.

42 Ovde, Mêt. III, 158; OpPIEn, Cyn. IV (19), 280-238 (édit. P. Boudreaux, 1908) : "d'autrefois il égorgeait des brebis, les dépouillait de leur toison, les coupait en morceaux et les jetait sans vie sur la terre, puis il rejoignait exactement leurs membres »(trad. M. Belin de Ballu).

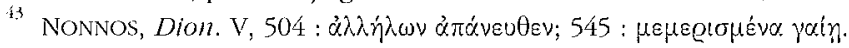


l'archétype de la série, le psykter d'Euphronios, les artisans ont tiré une composition, formulaire et paratactique, caractéristique des versions que les imagiers de l'époque sévère ont laissées de l'épisode ${ }^{44}$. Mais il advient que, derrière l'apparence figée du défilé, les mouvements imprimés aux corps des ménades arthrophores suggèrent la dynamique du jet. Sur le stamnos d'Oxford du P. de Berlin ( $P$ l. VI, 3), les Cadméennes lancent avec violence, qui les jambes, qui les viscères, de Penthée. Les corps s'arquent, les bras se tendent vers l'arrière, de manière à jeter les chairs ensanglantées. De la même manière, sur la coupe de Douris, l'attitude de la ménade, penchée jusqu'au déséquilibre, rappelle le tournoiement du discobole qu'évoquait, au demeurant, dans les textes poétiques le verbe diarbiptô $(P l . V T, 2)$.

Loin du théâtre et de la fiction picturale, un témoignage épigraphique provenant de Milet et daté du III ${ }^{\mathrm{e}}$ siècle av. J.-C., vient conforter la réalité de la dissémination rituelle. Relatif à la vente du sacerdoce de Dionysos, le règlement, gravé sur un bloc d'ante, confirme la préséance de la prêtresse du thiase public lors des katagôgia de Dionysos en cette ville : « quand la prêtresse célèbre au bénéfice de la cité les saints orgia, il est interdit de "lancer l'ômophagion » avant que la prêtresse l'ait lancé au bénéfice de la cité " $^{45}$.

Il est vraisemblable que le texte, contemporain mais plus mutilé, du papyrus de Gourob, où le terme ômophagion ne figure pas, faisait plus vraisemblablement allusion à des rituels initiatiques. Le jet y est toutefois évoqué, limité cependant au "lancer dans une corbeille » d'une chose dont la nature n'était pas, ou, en raison de l'état lacunaire du document, ne se trouve plus précisée ${ }^{\text {it }}$.

Le lancer rituel n'est au demeurant pas dépourvu de parallèles dans d'autres fêtes dionysiaques ${ }^{47}$. À Lerne, où se perpétuait encore au II siècle de notre ère un ancien rite d'évocation, on suscitait l'épiphanie de Dionysos Bougénès, le "Gardien des Portes », au son de trompes, tandis qu'on jetait simultanément dans les eaux du lac des agneaux vivants ${ }^{48}$. En dehors du contexte dionysiaque, le lancer de porcelets vivants dans des fosses était perpétré dans toute la Grèce au premier jour des Thesmophories ${ }^{49}$.

4 Arthophorie : psykter d'Euphronios, stamnos d'Oxford du P. de Berlin, coupe de Douris (revers) (cf. réf. n. 29), coupe du Louvre G 69, Nicosthénès, ARV 133, 2; LllkC VII, s.v. Pentheus, 41; hydrie maniériste de Berlin 1966.18, LIMC VII, $i b$., 40; I. Th. Kakridis, Hellinikê Wytbologia III, Athènes, 1966, p. 75, fig. 40.

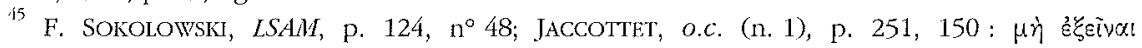

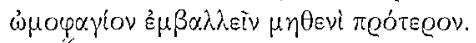

Papyrus de Gourob I, J. GILBART SinLt, Greek Papyri from Gourob, 1921, p. 10, 1. 28 : «( $\alpha$ $\delta \varepsilon 1) \varepsilon t \sigma \quad x \alpha \lambda \alpha \theta 0 \nu \varepsilon \mu \beta \alpha \lambda t \nu »$. Les crepundia, cités ligne 29, pouraient-ils avoir été l'objet de ce lancer?

17 Pour Corinthe, PINDARE (Ol. XIII, 18) s'interroge sur l'origine de la fête où était pratiqué le «lancer d'un bouf » (boelatès).

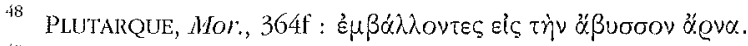

19 Scholie à LuCIFN, Dialogue des Comtisanes, II, 1, dans L. DeubNrr, Attische Feste, Berlin, 1932 [1956], p. 40, n.5. 


\section{Les directions du lancer : anô katô}

Codifiée, la gestuelle de la dispersion confère au lancer des parts sa symbolique propre. Le jet s'effectue selon des gestes pendulaires qui ne sont pas sans rappeler les fléchissements des corps dans la transe et le frappement des torches et des thyrses contre terre, autant d'attitudes contrastées qui s'apparentent aux appels cadencés des rituels d'éveil. Les directions contraires imprimées au lancer sont exprimées par les adverbes anô et katô. Au vers 741 des

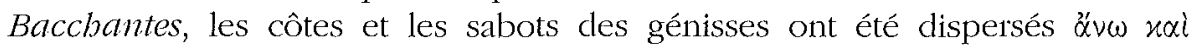
$x_{\alpha}^{\alpha} \tau \omega$, littéralement de haut en bas et de bas en haut et demeurés accrochés aux cimes des sapins. L'antithèse haut/bas définit un axe vertical reliant ciel et terre dont la symbolique outrepasse la mécanique des gestes et rend compte du fait que le rituel se soit perpétré au sommet des montagnes, situées à michemin dans la géographie mythico-cosmique antique ${ }^{50}$. Les directions du jet paraissent avoir été affectées d'une signification proche de celle que la mythologie orientale conférait aux termes ciel $(a n)$ et terre $(k i)$, synonymes de haut et de bas.

Les parts des génisses qui ont été lancées en l'air sont demeurées suspen-

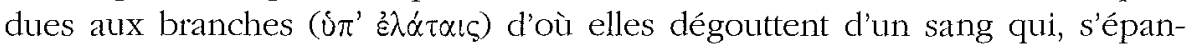
dant verticalement en direction du sol, matérialise la jonction entre ciel et terre. Quant aux restes de Penthée, dispersés en direction du sol et de l'éther,

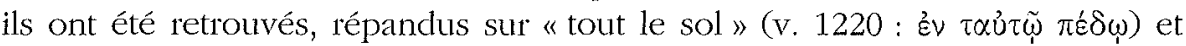

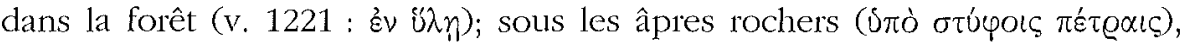

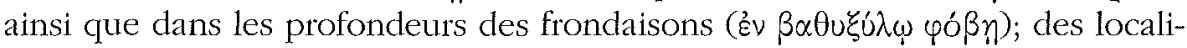
sations qui ne sont pas dues au hasard de jets désordonnés, mais qui découlent des directions axiales qui ont présidé au lancer lors des deux sparagmoi : le bas (sol, anfractuosités), le haut (sapin, frondaisons, forêt).

L'axe haut/bas est à ce point caractéristique des techniques du rituel qu'il se voit évoqué, au moyen des mêmes adverbes, dans des allusions prémonitoires au sparagmos de Penthée. En marge de l'action rituelle, ces directions sont rappelées dans des contextes où toujours se manifeste la violence, celle de Dionysos comme celle de ses opposants. On les voit mentionnées dans les menaces proférées contre Tirésias par Penthée qui veut retourner et bouleverser $\ddot{\alpha} v \omega$ x $\alpha \tau \omega$ le siège augural du devin ${ }^{51}$; dans la description de l'effondrement

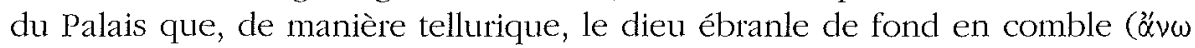
$x \dot{\alpha} \tau \omega)^{52}$; dans le déferlement des ménades, enfin, qui, depuis le Cithéton,

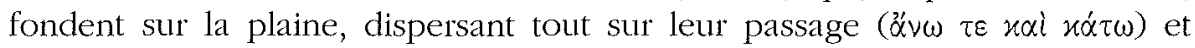
dont Euripide relate les pillages au moyen du verbe diapherô qui connote usuellement le déchirement ménadique ${ }^{53}$.

50 Cf. R. Buxton, La Grèce de l'imaginaire, Paris, 1996, p. 101; M. Halm-Tisserant, "Sparagmos et Cithéron ", in $X^{*}$ Colloque surla Bëotie anlique, Montréal, 2001, sous presse.

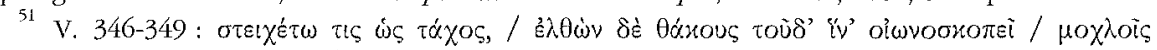

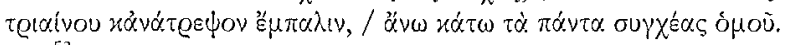

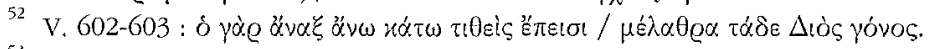

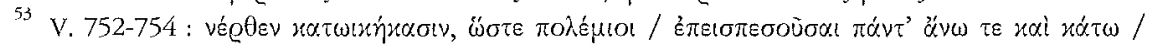

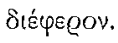


L'axe est encore suggéré, mais sans que soient employés les adverbes de lieu, dans l'installation et dans la chute de Penthée, depuis le pin où il espionnait les Ménades ${ }^{5 i}$. Il est plus fortement concrétisé par l'éclair qui, sonnant la mort du roi, vient depuis le ciel frapper la terre ${ }^{55}$.

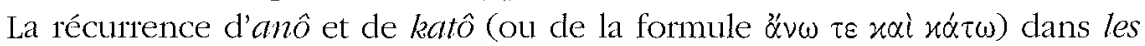
Baccbantes est d'autant plus porteuse de sens que l'on rencontre cette même locution adverbiale dans le texte du papyrus de Gourob ${ }^{56}$, où l'expression anô katô est présentée comme un synthèma, un formulaire sacré du culte. L'occurrence de cette locution, que le témoignage épigraphique présente comme une formule rituelle, tant dans la description du premier sparagmos que dans des situations extérieures au rite où elle se trouve apparemment banalisée, incite à considérer la tragédie d'Euripide comme une pièce à clé, livrant certaines des arcanes du rite, intelligibles des seuls initiés ${ }^{57}$.

L'usage d'un vocabulaire précis pour en évoquer les séquences, la constance des représentations figurées montrant le sparagmos, démontrent que, jusque dans la fiction, les monuments font référence à un rite réel et qu'il ne faut donc négliger aucune source pour sa compréhension. Signifiantes apparaissent aussi les concordances des témoignages, tous genres confondus. L'image vasculaire, la fiction poétique, comme les témoignages historiques et épigraphiques évoquent des modalités semblables, des gestes ritualisés, voire même des formulaires liturgiques. L'univocité des témoignages, favorisant l'étude des actions et de la gestuelle du sparagmos, permet d'en entrevoir la signification.

\section{Finalité du sparagmos}

Par la verticalité de l'axe qu'elle suit, la dispersion des parts a pour but d'apporter à la terre (katô) l'énergie vitale contenue dans la chair dépecée vive, encore fibrillante. Car le verbe sparassô, s'il signifie bien mettre en pièces, connaît une autre acception : celle de palpiter ${ }^{58}$. Le germe de vie frémissant demeuré dans la part crue - que l'on nommait à en croire les réglements cultuels ômophagion - est censé régénérer les principes de génération universels que sont Ciel et Terre. Le lancer vers l'éther (anô) avait-il, comme le tir à l'arc contre le soleil dans la mythologie de la Chine ancienne, la faculté de capter l'énergie du feu solaire ${ }^{59}$ ? ou, plus vraisemblablement, comme cela

${ }^{54}$ Maintenue par Dionysos, la cime de l'arbre est abaissée «jusqu'au sol noir » (v. 1065 : Eị

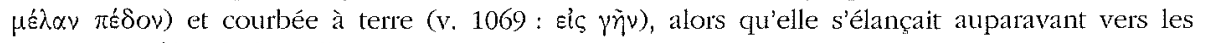
cieux (v. 1064 : oủé́vtov äxอov).

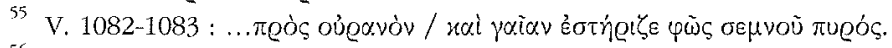

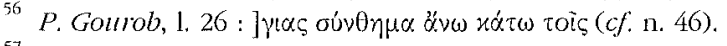

57 D'autres formules, presque glossolaliques, semblent empruntées à des bieroi logoi ou à des

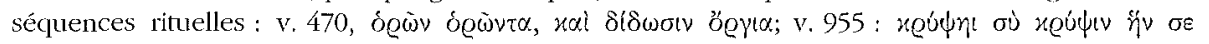

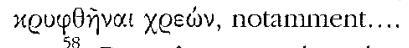

58 De même que le substantif sparagmos peut encore désigner le spasme: fr. 165 des Xantriai d'Eschyle (Mette [1959], p. 368). Cette fibrillation évoque l'épiclèse de Bromios, le Frémissant, sous laquelle Dionysos était particulièrement honoré.

59 M. GRANET, La civilisalion chinoise, 1932 [1994, Albin Michel], p. 223. 
est attesté dans d'autres cultes «agraires » en Grèce (au moyen notamment d'exhortations adressées aux mondes d'en haut et d'en bas, telles la formule "mouille, féconde" du rite éleusinien des ploemochoés) de garantir la permanence de l'étreinte génésique du ciel et de la terre ${ }^{(i)}$ ?

Même lorsqu'il aura été ritualisé, comme semble le démontrer le règlement milésien $^{61}$, le lancer aura gardé l'essentiel de sa symbolique fécondante, exprimée par la perpétuation de gestes calqués sur ceux de la sémination. Car le lancer est par définition le geste du semeur; que ce soit dans lá réalité des travaux agricoles ou dans les récits mythiques d'anthropogénèse. Lorsque, à l'issue du déluge, Deucalion sème une nouvelle humanité ${ }^{62}$, il «lance »les pierres dans les sillons de la terre. De la même manière Cadmos, en lançant les dents du dragon dans le sol suscite la génération des Spartoi dont le nom - Hommes semés - dérive du verbe speirô qui signifie à la fois éparpiller et semer $^{63}$. L'action de lancer équivalant dans l'imaginaire des Grecs à celle d'ensemencer, c'est encore le geste génésiaque que, dans la Théogonie, Hésiode a prêté à Cronos lorsqu'il «lance par derrière ${ }^{6+1}$ » les bourses d'Ouranos. Contrairement à la fiction littéraire qui recourut à un spectre plus large (emploi des verbes diapberô, rbiptô, diarbiptô, dikô), le langage rituel, précis parce que formulaire, usa pour désigner le jet du verbe emballô, rencontré à la fois dans les témoignages épigraphiques et dans l'évocation du rite de Lerne ${ }^{65}$. C'est encore le verbe qui est à plusieurs reprises utlisé par le scholiaste de Lucien ${ }^{\text {6́, }}$ afin de désigner le lancer des porcelets vivants dans les megara, lors des Thesmophories, une fête liée aux semailles. Le verbe emballô a au demeurant le métite de clarifier des épiclèses divines, originellement liées à un rite de dispersion, telles que celle qui était attribuée à Dionysos Aigobolos, Lanceur de chèvres à Potniai, ou celle d'Elapbébolios, lanceur de faon, qu'on donna à Artémis, mais qui se rattache d'autant plus sûrement à la sphère dionysiaque

61) Précédé de mascarades et de joutes aischrologiques, le rituel - agraire et funéraire - se

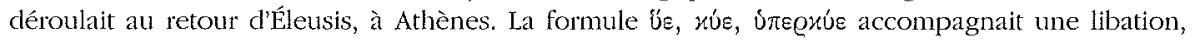
Origène (Hippolyte, Pbilosoph. V, 7, p. 104 Miller); Dictionnaire des Aniquiless, s.v. Eleusinia, p. 573; G. MYlonas, Eleusis, Princeton, 1961, p. 305.

G. C. p. 130 et n. 45.

62 OVIDE, Mêt. I, 344; 394 (verbe iacere).

${ }^{63}$ Euripide emploie le verbe dikô pour exprimer cette sémination dans les Phéniciennes, 665-699. Même vocabulaire pour connoter l'acte de Cadmos dans le poème de NoNNOS, Dion. IV,

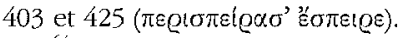

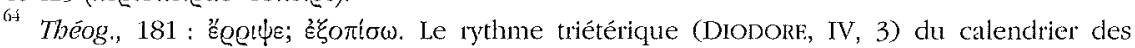
fêtes ménadiques découle de la pratique de la jachère, voir G. CASADıo, ll vino dell'anima, Rome, 1999 , p. 154.

65 Aphièmi, PAUS., IX, 8, 1, pour évoquer le rite thesmophorique en Béotie. C'est parce que emballem ressortit au vocabulaire liturgique que l'emploi du verbe bypoballô, dans le discours insane de Penthée (v. 950) a toute chance de faire référence à des formules (ou à des gestes) dont le sens nous échappe; allusion à une technique de lancer différente qui s'apparenterait plus strictement à celle du semeur qui, tel Deucalion dans les Mélamorphoses d'Ovide ou Cronos dans la Théogonie, avançant le long des sillons, lance le grain « en arrière "?

${ }^{6}$ Schol. à LuCIFN, $c f$. n. 49. 
que cette épithète désignait le nom du mois durant lequel se déroulaient à Athènes les Grandes Dionysies ${ }^{67}$.

Les modalités du lancer dionysiaque semblent avoir été doubles.

Par le contact direct du sang qui s'écoule des parts crues vers le sol, le sparagmos s'apparente aux rituels chthoniens. La libation de sang paraît avoir à ce point été déterminante dans le processus de sémination que les poètes l'ont associée au lancer dans les récits de génération et d'anthropogénèse. C'est au contact des giclées sanglantes, jaillies des bourses tranchées d'Ouranos, que Cronos a, au préalable, lancées du haut des cieux, que naîtra l'ultime progéniture de Gaia ${ }^{18}$. Et, par l'écoulement du sang des Spartes qui, sitôt issus du sol se massacrent, une libation chthonienne qu'Euripide évoque dans les Pbéniciennes suit l'ensemencement de la terre, fécondée par les dents du dragon ${ }^{69}$.

Par l'offrande de la chair crue, en revanche, c'est davantage du côté de la magie fécondante que fait regarder le sparagmos dont Tirésias, dans Les Bacchantes laisse d'ailleurs à entendre la grande ancienneté, le sacrifice étant «enraciné au fond des âges » et "issu de la nature même »". Comme pour d'autres pratiques perpétrées en Grèce ancienne, ces techniques dérivent de rites préhelléniques de fertilité qui, en dépit de variantes structurelles, ont transmis à ces cultes, toujours violents, un tréfonds commun, impliquant de mettre en ouvre des modalités relativement semblables.

On se souvient que, dans les Bacchantes, les bovidés ayant été démembrés, les ménades lydiennes déferlent vers les bourgs du Cithéron, tandis que les princesses cadméennes regagnent Thèbes, porteuses du trophée de chasse, qu'en dépit de leur folie elles n'ont pas lancé, la tête de Penthée. Sitôt la dissémination accomplie, les membres du thiase se retirent. À l'issue du sparagmos les parts des victimes sont donc abandonnées au sol et aux arbres, apparemment vouées à une fertilisante putréfaction ${ }^{71}$. On ne peut s'interdire d'établir un parallèle entre la finalité du sparagmos et celle du rituel de l'Anodos durant lequel, au premier jour des Thesmophories, étaient lancés pêle-mêle dans les profondeurs des mégara où ils étaient abandonnés jusqu'à leur décomposition, des porcelets vivants et de jeunes pommes de pin (éminemment dionysiaques !), choisis en raison de leur exceptionnelle fécondité $^{-2}$. Le cycle de la putréfaction dans les fosses étant achevé, les «Éco-

${ }^{67}$ Potnial : PaUs., IX, 8, 1; Athènes, voir JEanmaire, o.c. (n. 7), p. 265 qui demeure l'un des trares auteurs à avoir perçu et souligné l'importance du lancer dans le sparagmos, quand bien même il a assimilé cette pratique aux rituels de transe et de dévoration des sectes d'Afrique du Nord.

HÉs., Thëog., 138.

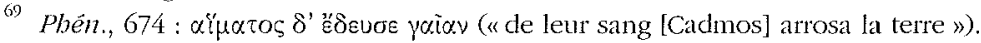

7li Bacch., 895; 201. Voir le commentaire qu'a consacré à ces passages J.-P. VERNANT, Mythe el pensëe chez les Grecs I, Paris, 1978, p. 13.

${ }^{71}$ Compromise par Cadmos, parti en quête des membres de Penthée, qui atténue ainsi la déviance que représente la mise en pièces du roi, par rapport au sparagmos animal.

${ }^{72}$ Voir n. 49. L'évocation des replis de terrain (Bacch., 1220), des anfractuosités que suggère

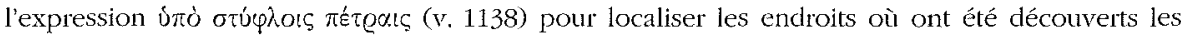


pettes " - nommées du nom féminisé de l'escope avec laquelle on vidangeait l'eau croupie dans les sentines - remontaient la pourriture qu'elles mêlaient ensuite au grain destiné aux semailles. Lancées vivantes, les victimes étaientelles au préalable l'objet d'un sparagmos, garant d'un surcroît d'efficacité, leurs viscères, telles les parts mises en pièces, se trouvant en pareil cas au contact direct du sol des fosses? Contrairement au lécythe du Musée d'Athènes ( $P l . I, 3)$, les terres cuites du Thesmoplborion de Thasos, présentant les corps longitudinalement fendus et distendus des porcelets, le laisseraient du moins supposer...

Il est de l'ordre des choses que les rites de magie fertilisante aient été du ressort des femmes, principes de fécondité par excellence, elles dont le sexe était métaphoriquement assimilé à un champ destiné au labour ${ }^{73}$. S'y trouvaient immolées des victimes vivantes dont l'énergie puis la dégradation de leurs chairs étaient, in fine, destinées à éveiller, non seulement la croissance végétale, mais encore toute forme de génération. De même que les actions de lancer et de semer avaient été confondues dans la pensée antique, sémination et putréfaction étaient perçues en terme d'équivalence, en raison du rôle accordé au principe humide (précisément incarné par le Dionysos Hyès) dans les cycles de la germination et de la procréation ${ }^{74}$. La nature même des victimes anéanties lors de l'Anodos conforte les relations entre fertilité agraire et fécondité humaine, d'ailleurs soulignées par le scholiaste de Lucien pour le contexte démétriaque. Car, le nom que portait en grec l'animal lancé dans les megara - choiros - servait aussi à désigner les pudenda muliebra que Diony-

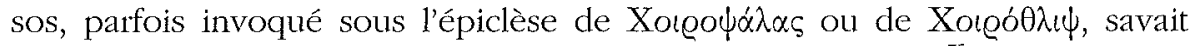
"presser» ou «faire vibrer», en prélude à l'union sexuelle ${ }^{75}$. Tout comme celui de la terre (que les Thesmophores se soient assises, sexe contre terre, ou qu'avant le sparagmos, les ménades se soient laissées « choir à terre » (Bacch., $136: \pi \varepsilon \sigma \eta \eta \varepsilon \delta \delta \sigma \varepsilon$ ), le contact du sang avec les corps devait exacerber l'efficacité de la magie fécondante. On ne saurait manquer de rapprocher la pratique, rapportée par Élien, qui imposait aux femmes de s'enduire le visage et les mains du sang frais des victimes sacrifiées lors des Thesmophories, de l'évocation, aux vers 698 et 768 des Bacchantes, des serpents venus lécher sur

restes de Penthée, appelle l'image chtonienne des failles artificielles dans lesquelles étaient jetés les porcelets lors des Thesmophories.

73 M. GarCla Thueiro, «Langage orgiastique et glossolalie », Kemos 5 (1992), p. 60.

7 Dionysos Hyès, Etym. Magnum, 775, 3; Limnaios à Lerne (G. CASADIO, o.c. [n. 64] p. 92); sur les équivalences, humidité / putréfaction / génération : PluTArque, De Iside, 35, 69 (Mor.,

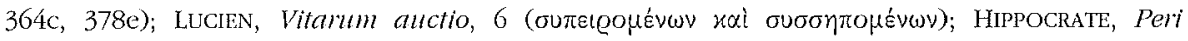
Pbysios Paidiou XXII, 4; XXIII, 3; plus généralement M. DetIENNE, Les Jardins d'Adonis, Paris, 1972, p. 97.

${ }^{75}$ C'est le Dionysos "palpeur de chattes », pour respecter en français la comparaison établie par les Grecs entre le sexe féminin et l'animal. Sicyone, FHG I, 135 (schol. Esch., Perses, 1033); Clém. Alex., Protr, 39; POLÉM., Hist, 72. 
les joues des ménades le sang que dans le même temps elles nettoient sur leurs mains ${ }^{76}$.

Toutefois, la réussite de l'action magique s'opérait par la réduction à un état contraire à celui qu'on entendait susciter : du cycle de la décomposition renaissaient le grain de Déméter et la végétation que suscite Dionysos, de même que l'abstinence ou la tempérance sexuelle ${ }^{77}$, favorisée par le contact de plantes humides (gattilier des Thesmophories; lierre dionysiaque), stimulait la fertilité des femmes.

En tant que ptincipes conjugués de l'Humide et de la Sève ${ }^{78}$ et par delà le rite de magie agraire, Dionysos dispensait la fécondité dans ses composantes végétale, sexuelle et cynégétique ${ }^{79}$, suscitée par des pratiques «nées de la nature » et demeurées vivantes parce qu'entretenant avec elle un rapport fusionnel $^{80}$. Alors que dans le rite démétriaque (qui, s'étant adapté aux exigences d'une héortologie citadine s'était coupé de la nature) la putréfaction fertilisante s'opérait presque industriellement dans des fosses artificielles, le contact des parts - semence et engrais tout à la fois - avec l'éther et le sol conférait au lancer dionysiaque une symbolique cosmique. Quand bien même, en raison des lois de la gravitation, le ciel demeurant inaccessible, le jet ne permettait de répandre les parts qu'aux règnes végétal et minéral, le lancer dionysiaque était grevé d'une dimension panthéiste qu'ignorait le rite thesmophorique ${ }^{81}$, d'ailleurs exprimée dans la fiction tragique par le fait que la nature entière participe à la Bacchanale ${ }^{82}$.

Tenir le sparagmos dionysiaque pour un rituel d'ensemencement de la nature a pour contrepartie d'ôter à l'ômophagie sa raison d'être. La prêtresse ou l'adepte qui le pratiquait n'était qu'un relais, qui, telles les «Écopettes » ou le semeur, disséminait les parts crues. S'il est un convive susceptible, en

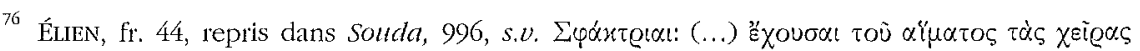

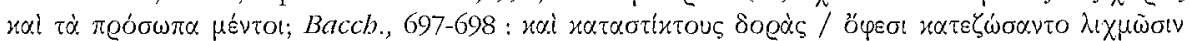

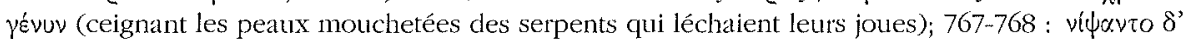

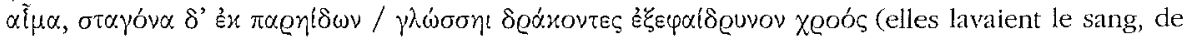
leurs langues les serpents nettoyaient celui qui dégouttait de leurs joues).

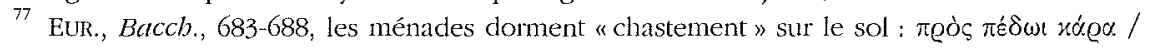

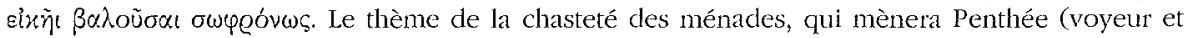
inversement persuadé de leur conduite lascive) à sa perte, soustend d'ailleurs le drame des Bacchantes.

${ }^{7}$ Aunitès (Paus. VII, 26, 1), Pbléos, Phlios (JFAnmatre, o.c. [n. 7], p. 140; 237; 442), Pbytalmios (Plut, Mor: 158e), Problastos (schol. Lyc., 577; DaraKi, o.c. [n. 6], p. 32).

${ }^{79}$ Sous l'épiclèse de Zagreus, privilégiée dans les milieux orphiques, Dionysos est un chasseur, fonction que connote également l'épithète Agrionios (PluT., Ant., 75, 4) et qui est mise en évidence dans les Bacchantes, 1145, 1191 p. ex.

81. Dans le drame d'Euripide, elle participe au rite, coîte lorsque meurt Penthée (1084), entransée (726) dans l'extase collective qui prélude au premier sparagmos.

${ }^{81}$ Les pouvoirs du Gonoenta ont suscité d'autres rites, parmi lesquels culminait, lors des Anthestéries à Athènes, l'union sexuelle avec la Basilinna qui assurait à la cité descendance et prospérité. Henrichs, l.c. (n. 5), p. 256, tient l'héortologie dionysiaque, grâce à l'énergie que transmet Dionysos, pour un rituel de régénération périodique des cités.

${ }^{82}$ Cf. note 80. 
revanche, d'avoir bu la libation de sang et de s'être repu des chairs dépecées, c'est la nature entière, consubstantielle au demeurant du dieu « tueur de bouc, ômophage, » pour lequel «chassent » les Bacchantes ${ }^{83}$ et que l'on honorait à Chios dans la complétude de sa double nature, en tant que Phleus et Omadios $^{8 \cdot 4}$.

C'est à de tels festins qu'a vraisemblablement songé Euripide dans les Crétois lorsque, dans une profession de foi végétarienne, le bacchant évoque «les repas ômophages » qu'il a accomplis pour le «bouvier Zagreus, le rôdeur nocturne ».

M. HALM-TISSERANT

Université de Franche-Comté

Pavillon d'archéologie

31, rue Mégevand

$\mathrm{F}-25000$ BESANÇON

83 Bacchantes, 139-140: «Il est doux dans les montagnes, parmi les thiases agiles, de choir à terre, ayant pour saint vêtement la nébride, chassant le sang pour l'amour du tueur de bouc, ômophage » (trad. M. Halm-Tisserant). Rendre à l'incise une syntaxe grammaticale, suppose la

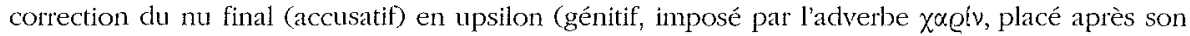
régime).

84 Dionysos "Jeune pousse » et "Carnassier », EUELPIS DE CARYSTOS, FHG IV, 408. 


\section{Planches}

Pl. I. 1. Coupe de Tarquinia 6848, Oltos (détail), $A R V$ 60,66, P. ARIAs, HIRMER, A History' of Greek Vase Painting, 1962, fig. 100.

2. Sarcophage étrusque du Musée Britannique B 22, LIMC VIII, s.v. Mainades, 114.

3. Lécythe d'Athènes MN 1695, ARV 1204, MDAI(A) 100 (1985), pl. 49, 3.

4. Coupe d'Onésimos, A. SCHNapp, Le chasseur et la cité, cbasse et érotique en Grèce ancienne, Albin Michel, 2000, fig. 58.

P1. I. 1. Pyxis de Heidelberg, coll. privée, LIMC VII, s.v. Pentheus I, RA 1982, 118, fig. 5.

2. Couvercle de pyxide, Musée Brit. E 775, man. du P. de Meidias, $A R V$ 1328, 92, LIMC VIII, s.v. Mainades, 33 .

3. Cratère à colonnettes apulien de Gotha, P. de Berkeley, RVAp I 268,54; LIMC VIII, s.v. Mainades, 45.

P1. III. 1. Lékanè d'Odessa, H. MetzGer, Représentations, 1951, Pl. I.

2. Coupe de Toronto, Coll. Borowski, Douris, ARV 451, 3; Quaderni Ticinesi XXIII, 1994, pl. VIII.

Pl. IV. 1. Lécythe de Syracuse 24554, P. d'Oenoklès, RA 1983, p. 243, fig. 6.

2. Skyphos d'Athènes MN 1246, P. de Schuwalow, ARV 1212 a; LIMIC VIII, s.v. Mainades, 13.

3. Stamnos du Musée Brit. 439 (détail), ARV 298, 1643, P. de Brygos, LIWC III, s.v. Dionysos, 151 .

4. Amphore du Cabinet des Médailles 357, P. d'Achille, ARV 987, 2, LLMC VIII, s.v. Mainades, 38.

P1. v. 1. Hydrie, coll. privée, P. d'Altamura, ARV 605, 65 bis; Th. CARPENTER, The Wasks of Dionysos, 1993 (Carpenter/ Farane éd.), p. 186, fig. 7.

2. Coupe de la Collection Robinson, Baltimore, Macron, ARV 463, 52, CVA USA, Robinson Coll. II, pl. XVI, 1 a-b.

3-4. Péliké maniériste de Berlin 3223 (Faces A et B), ARV 586, 47, LMMC VIII, 95, M.H. DELAVAuX-Roux, Les danses pacifiques en Gièce ancienne, 1994, p. 145, no 60.

P1. VI. 1. Coupe du Louvre G 160, Macron, $A R V 478,312 ; R A 1983$, p. 243, fig. 5.

2. Détail du bandeau de la face A de la coupe de Toronto, Douris.

3. Stamnos d'Oxford (croquis à vue, face B), P. de Berlin. 


\section{Planche I}

Fig. 1

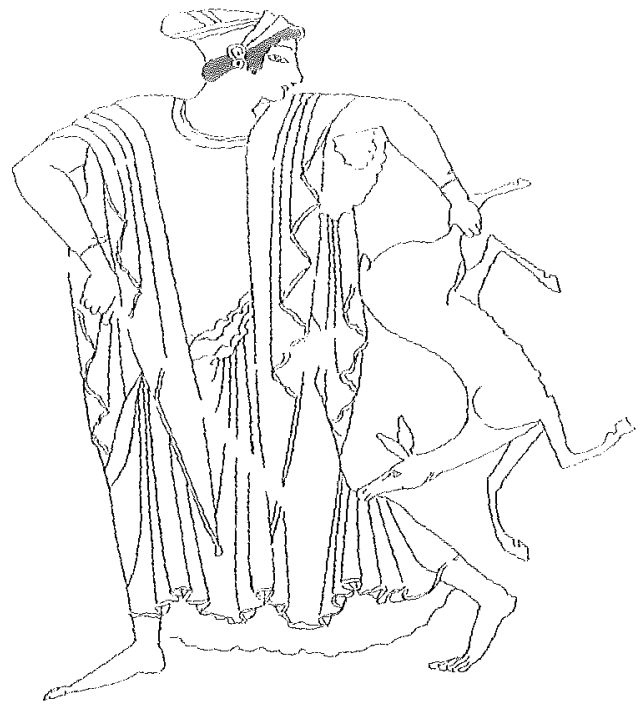

Fig. 2

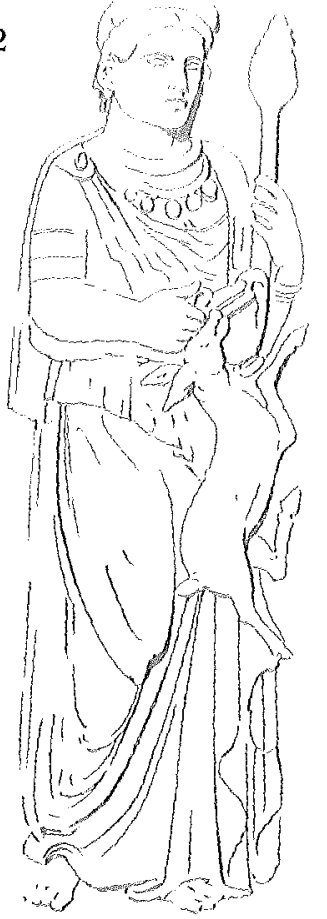

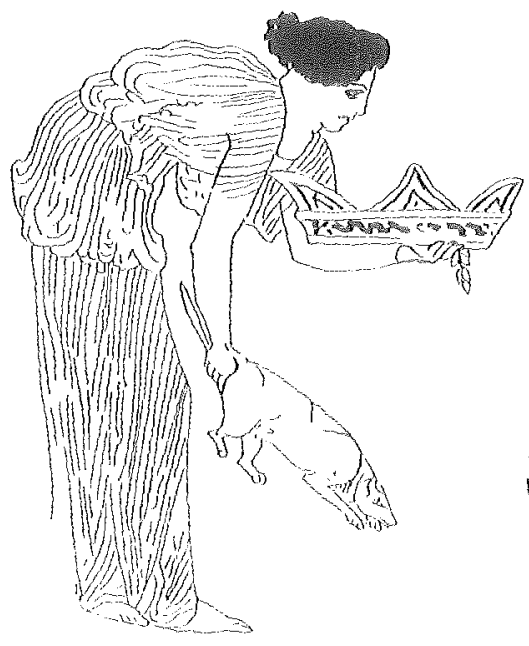

Fig. 3

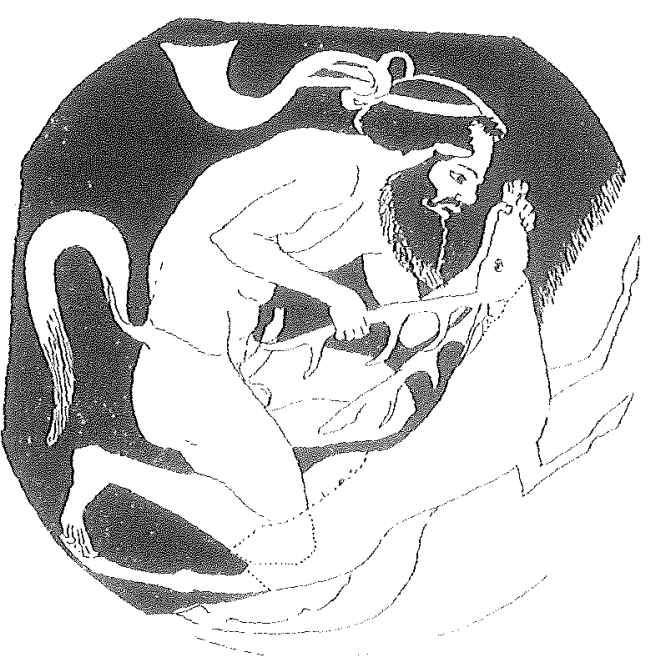

Fig. 4 


\section{Planche II}

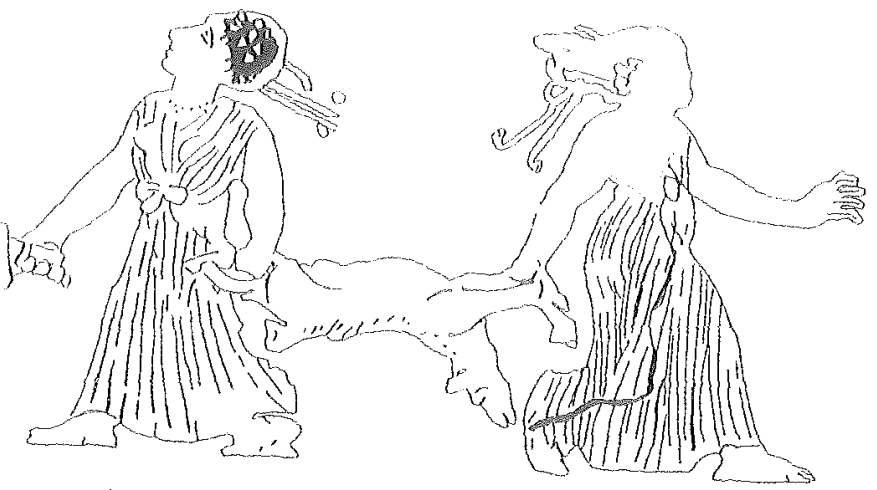

Fig. 1

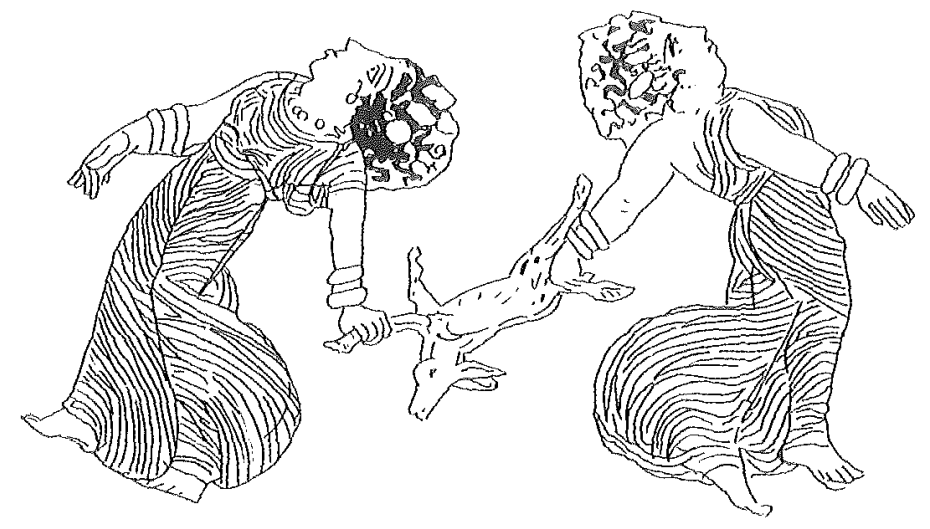

Fig. 2

Fig. 3

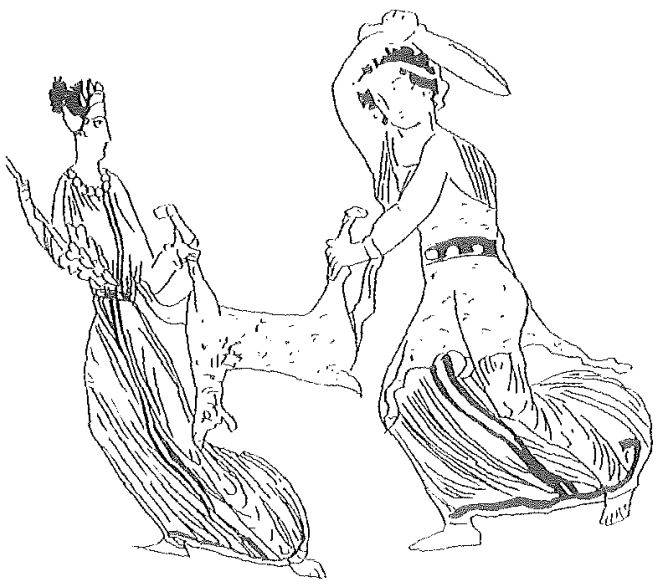




\section{Planche III}
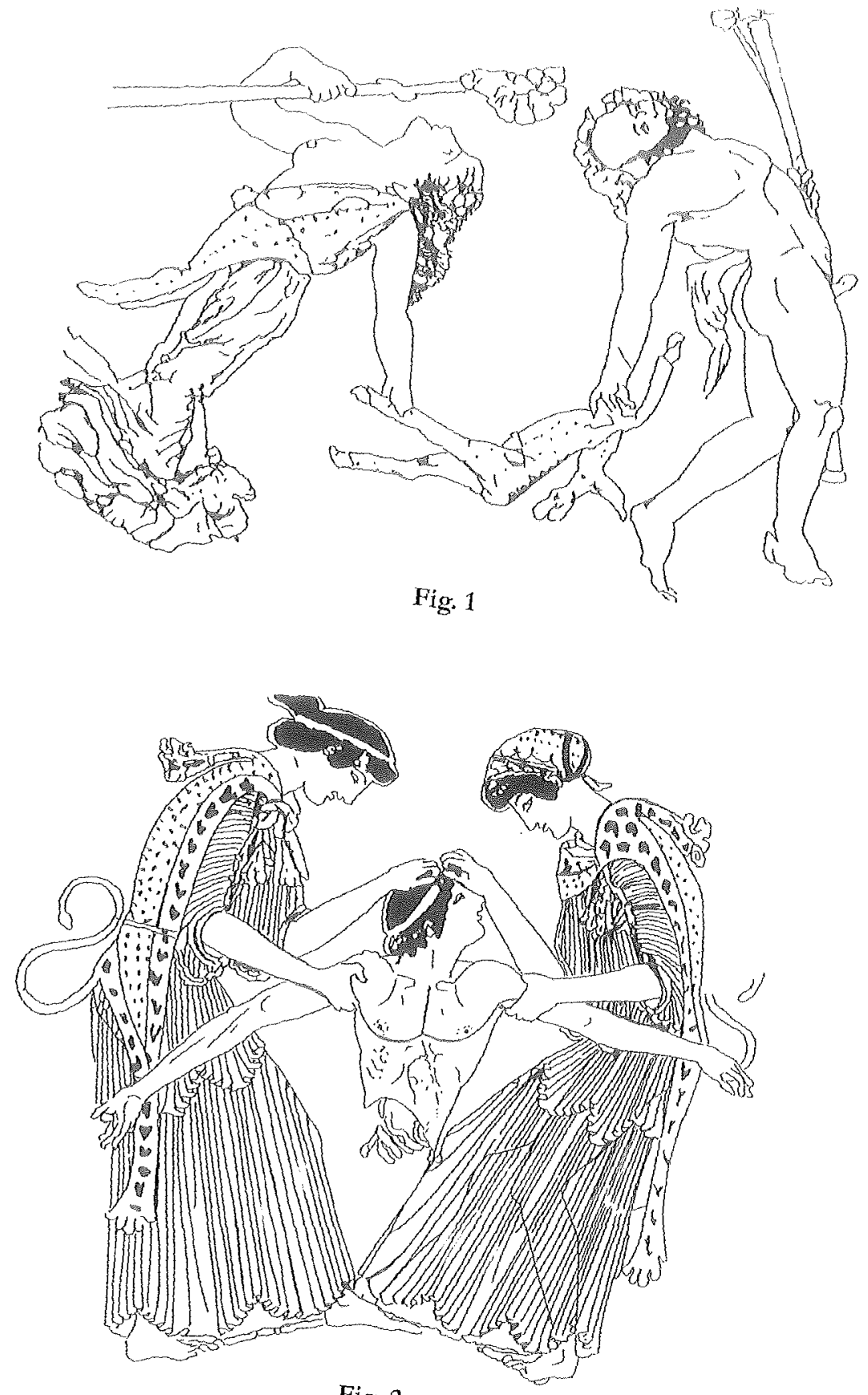

Fig. 2 
M. HALM-TISSERANT

140

Planche IV
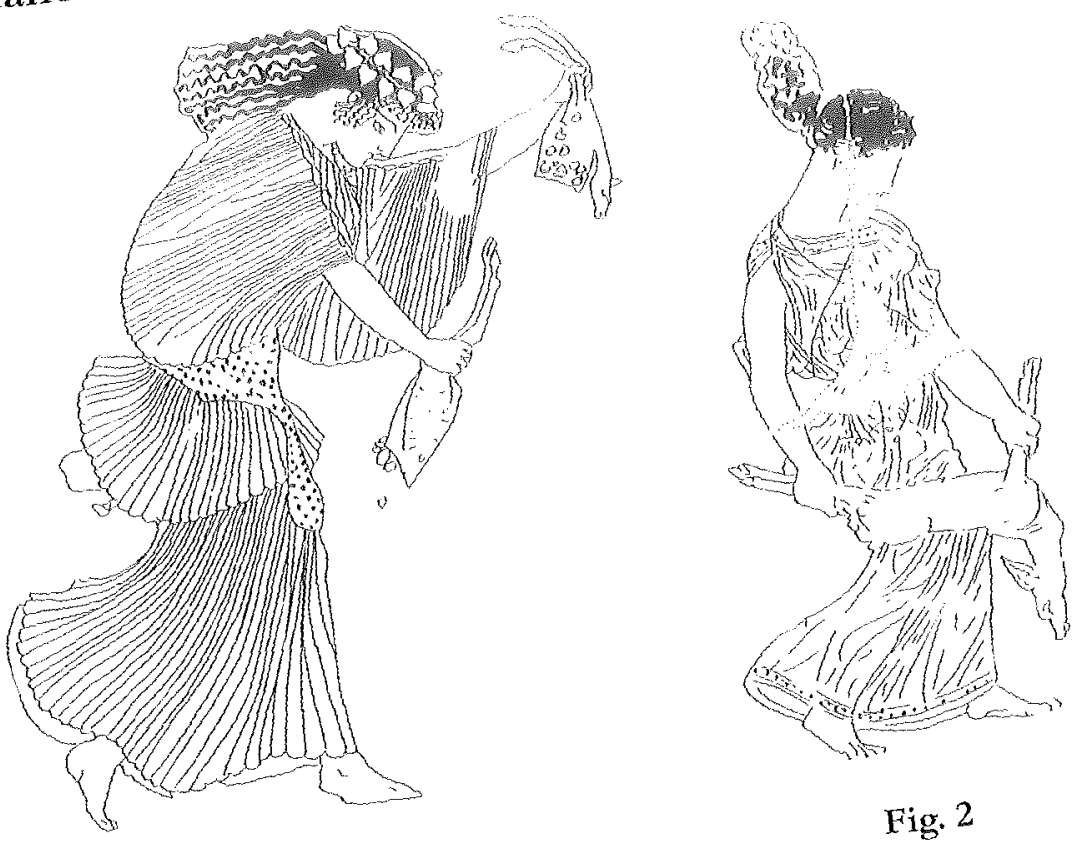

Fig. 2

Fig. 1

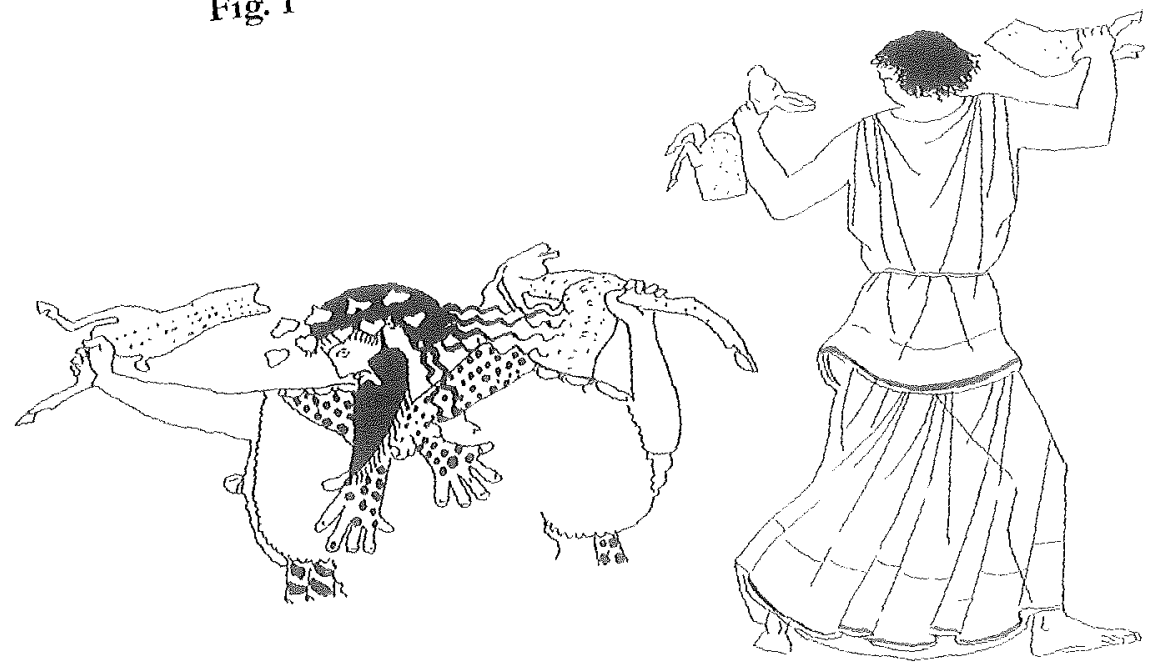

Fig. 4

Fig. 3 


\section{Planche V}

Fig. 1
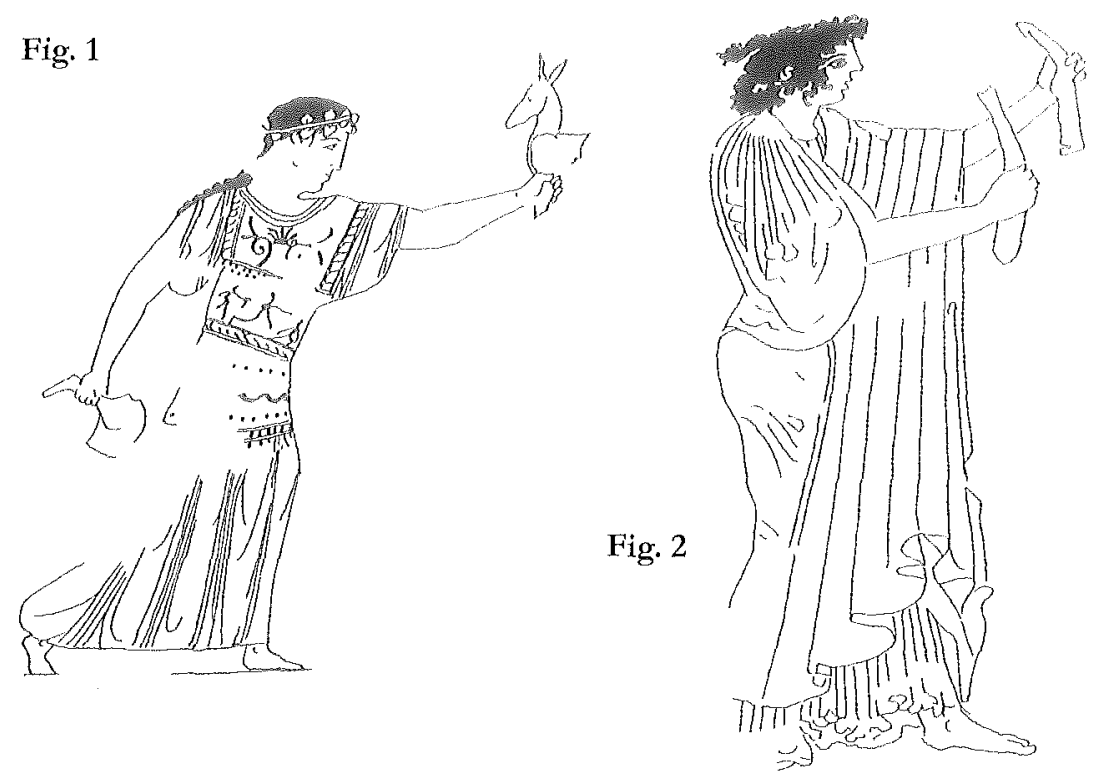

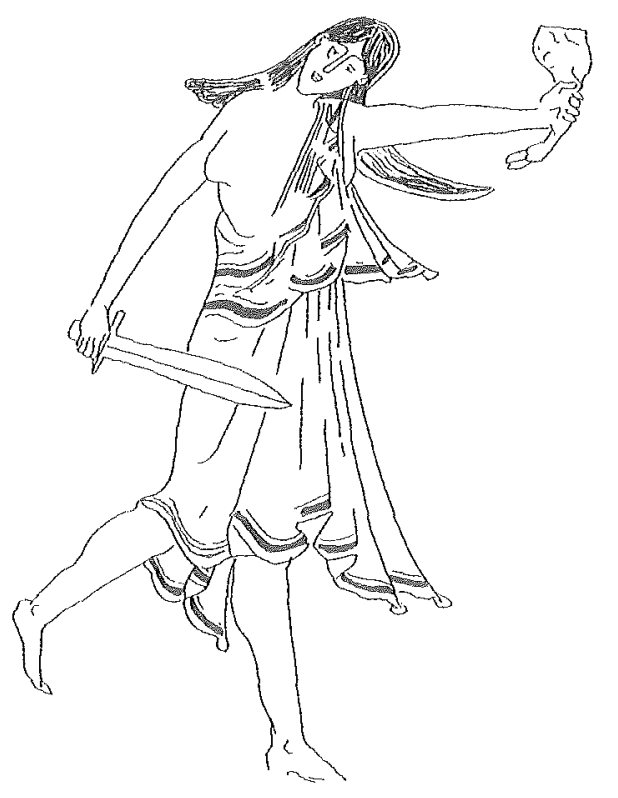

Fig. 3

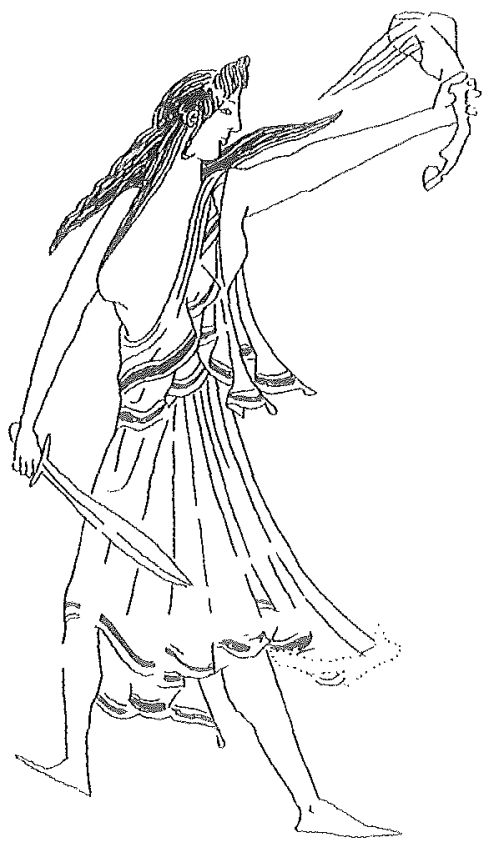

Fig. 4 


\section{Planche VI}

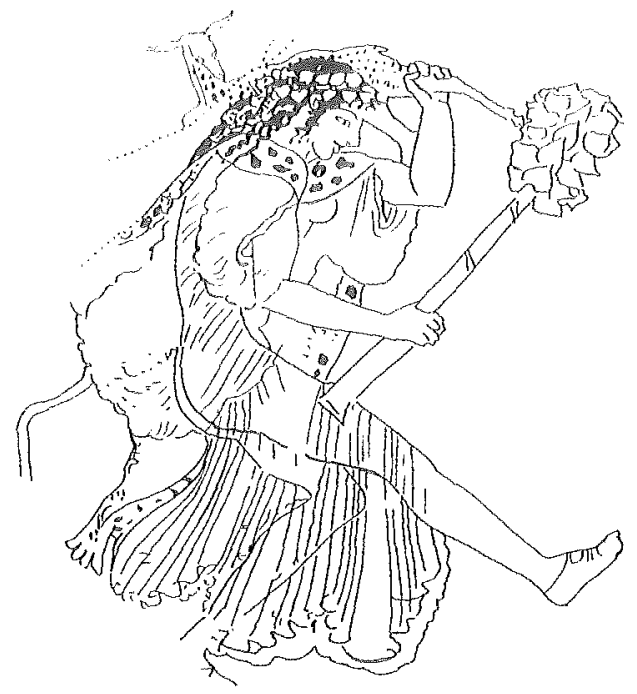

Fig. 1

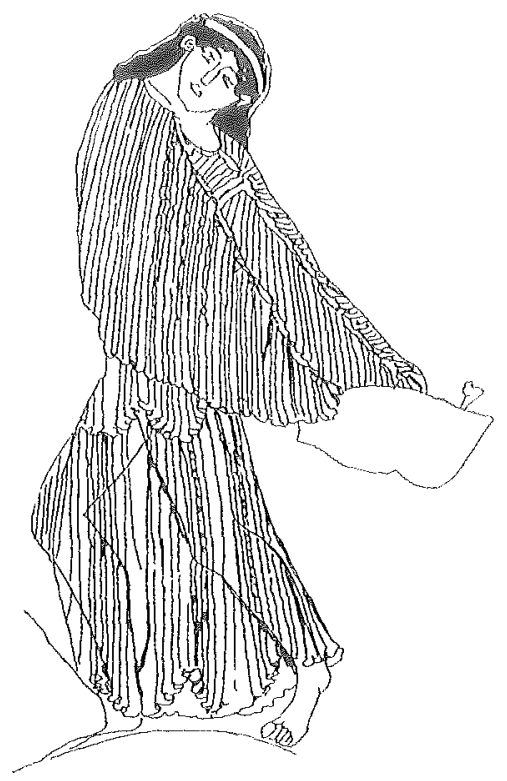

Fig. 2

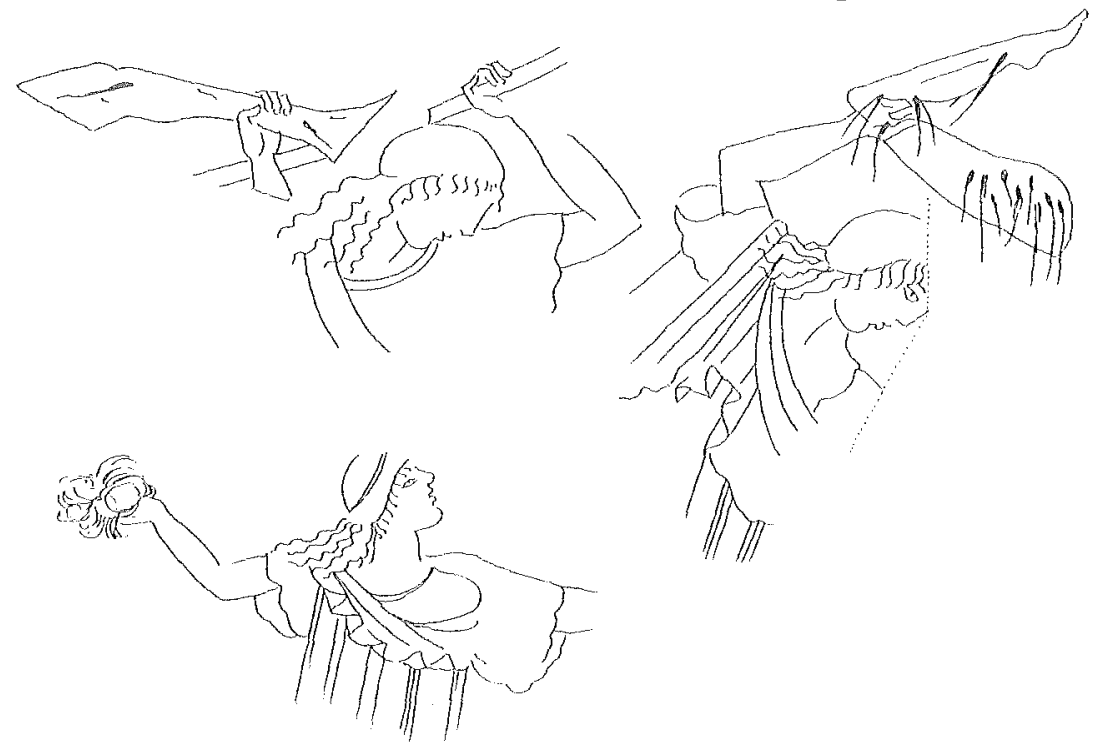

Fig. 3 